\title{
Simulation-Based Optimization for Yard Design at Mega Container Terminal under Uncertainty
}

\author{
Yong Zhou, Wenyuan Wang, Xiangqun Song, and Zijian Guo \\ State Key Laboratory of Coastal and Offshore Engineering, Dalian University of Technology, Dalian, China \\ Correspondence should be addressed to Wenyuan Wang; wangwenyuan@dlut.edu.cn
}

Received 19 May 2016; Accepted 30 August 2016

Academic Editor: Ricardo Aguilar-López

Copyright ( 2016 Yong Zhou et al. This is an open access article distributed under the Creative Commons Attribution License, which permits unrestricted use, distribution, and reproduction in any medium, provided the original work is properly cited.

\begin{abstract}
The conventional approach of designing a container yard should be reexamined in the context of sustainable port development. Considering the uncertain future throughput, a simulation-based optimization framework is proposed to obtain a cost-effective and reliable design solution to the physical layout and equipment deployment strategy of the yard at a mega container terminal. In this framework, a two-stage stochastic programming model is presented aided with a simulation procedure of terminal operations. Finally, an application is given and the results show that the proposed integrated decision framework is effective and helpful for optimizing container yard design in the context of sustainable development of container terminals.
\end{abstract}

\section{Introduction}

Worldwide container throughput has been steadily growing over the past decades. Between 1990 and 2014, the world's container trade expanded at an average annual rate of $8.4 \%$ [1]. Many ports, especially those in the countries with fastgrowing economy such as China, have gone through or are currently undergoing expansion of existing facilities or build-out of new terminals to cope with the increasing container traffic and ship size. However, the global maritime logistics market contains various uncertainties, such as world economy, trade policies, and freight rates, which results in a fluctuation of the demand for freight transportation $[2,3]$. For example, container trade volume fell sharply by $9.0 \%$ in 2009 due to the global economy crisis [4], and the volume of containers exported from China to US dropped by about $20 \%$ following 911 terrorist attacks [5]. Port infrastructure, especially the mega container terminal, is capital intense and serves long-term societal needs and thus should be reliable and adaptive to future uncertainties.

With the advancements of quay side technologies, the bottleneck of terminal operations has moved from quay side to yard side $[6,7]$. The design of container yard is a factor that affects terminal productivity and competitiveness. However, yard design is determined during the initial planning stage, when the available information and details are lacking [8], which may not be reliable during the future operation stage. In China, yard design in engineering practice addresses uncertainties through the introduction of an unbalance factor, the value of which is driven by experience. Yard block size and equipment deployment are also empirically determined $[9,10]$. This design approach easily gives rise to either an overallocation of yard resources or a low efficiency of terminal operation which is usually hard to be adjusted in the future. For example, the second phase of Yantian International Container Terminals (YICT) borrows part of the adjacent yard and rents off-dock yard in the peak period, which raises the difficulty in port traffic management and increases the operating cost. The cost resulting from the increment of trucks going back and forth between the terminal and offdock yard and venue rental for YICT reaches 25 35 million China Yuan (CNY) per year [11]. Therefore, a question arises naturally in an uncertain decision environment: how can we take into account future uncertainties in early stage of yard design, so that it is easier to adjust to random events in operation stage later on? This question is especially relevant to developing countries, where most terminals are not in place yet, thus presenting an opportunity to incorporate risks directly into the strategic planning of future infrastructure.

For designing a container yard, some researches focused on yard storage capacity estimation by advanced simulation models or analytical formula [12-15]. Other studies have 
sought to calculate the space requirement for planning [1618]. Once the main decisions about storage capacity and equipment choice have been made, the next step for planners involves the yard and block layout. Several studies on container terminal design have been conducted to compare parallel and perpendicular yard layouts using simulations $[19,20]$. Simulation and analytical techniques have also been used on yard design problem. For example, Petering [21] and Petering and Murty [22] developed a fully integrated simulation model to analyze the influence of the width and length of yard block on terminal performance. Kim et al. [23] proposed an analytical method to get the optimal yard layout. Kemme [24] examined the design of strategic yard crane systems and block layouts and their effects on terminal performance. Lee and Kim [25] attempted to determine the optimal size of a single block by taking into account the throughput requirements of yard cranes and the block storage requirements. They provided detailed formulae for the expected cycle times and variances of all yard crane operations. Lee and Kim [26] provided more detail on the expression of expectation of the yard crane cycle time for yard with different block layouts, useful for estimating yard crane operating costs. Lee and Kim [27] later determined the optimal layout of a whole container yard, as specified by the dimensions of a block and the number of aisles. However, none of these studies attempted to analytically determine storage space requirements by considering the stochastic properties of the storage yard. In view of this, Zhen [2] focused on the yard template planning problem under uncertainty. It considered the number of containers loaded onto (and unloaded from) each vessel within a cycle time as a stochastic parameter. Alcalde et al. [8] used an analytical model based on a stochastic approach (random variables and probabilistic functions) to forecast storage space requirements over an extended period. However, the optimized yard dimensions were not considered as optimal, because yard depth and block length were not optimized with the number of handling equipment deployed simultaneously.

Therefore, this paper will propose an optimization framework to obtain a cost-effective and reliable yard design solution that hedges well against uncertain future terminal throughput. This framework is composed of a simulation model for terminal operations and an optimization program with yard depth, yard block length, the quantity of handling equipment deployed, and the number of containers handled in the design yard as decision variables. The optimization program evaluates the capital costs and benefits of various yard layouts, while the simulation model emulates truck traffic and equipment moving at the terminal and calculates terminal efficiency indicators. The main contribution of this paper is simultaneously optimizing yard physical layout, equipment deployment, and storage schemes covering both planning and operation stages under uncertain environment, which would be more practical for yard design and management in developing countries, where the availability of data is often limited and the economic background is usually volatile. Although the analytical techniques used are not new (two-stage stochastic programming and system simulation), another contribution is essentially an integration of the techniques in a unique model framework, which is powerful for decision-making.

The remainder of the paper is organized as follows. Section 2 describes the procedures and their limitations when optimizing yard designs as well as yard design under uncertainty. Section 3 focuses on the modeling and solution method, including the proposed formulation and the solution framework for yard optimization. A numerical example and its computational results are given in Section 4, followed by discussions on advantages, limitations, and possible future extensions of this research in Section 5.

\section{Problem Description}

2.1. Quantitative and Qualitative Design Guidelines. The most commonly used layout format of a parallel yard with transfer lanes at manually operated terminals in China will be studied in this paper, as depicted in Figure 1. It is noted that container terminal operation generally consists of four components: seaside operation, horizontal transport, yard operation, and landside operation. At the seaside, containers are discharged from and loaded into containerships by quay cranes deployed along the coastline. Internal trucks are dispatched for transporting containers between quay cranes and certain storage stacks in the yard. Container yard can usually be divided into large zones and each zone is further composed of rectangular shaped blocks. Each block contains several lanes of space for storing containers in stacks and one lane for trucks to pick up and deliver containers. For the convenience of vehicular traffic, blocks are laid out in the unit of module, which combines two blocks with transfer lanes in back to back form [23]. Yard cranes, standing over a storage block space, can be transferred from block to block, to stack and shuffle containers. The landside operation is the task of receiving or delivering containers undertaken by external trucks. According to the MTPRC and several practical handbooks, input variables and the procedures to determine yard layout are as follows.

(1) The yard capacity $E_{y}$ and the number of ground slots $N_{s}$ are calculated as

$$
\begin{aligned}
& E_{y}=\frac{Q_{h} t_{d c} K_{B K}}{T_{y k}}, \\
& N_{s}=\frac{E_{y}}{N_{l} A_{s}},
\end{aligned}
$$

where $Q_{h}$ is the annual throughput of the container terminal; $t_{d c}$ is the average cluration of the containers, determined by the statistical material; $K_{B K}$ is the unbalance factor of containers stacked in the yard, determined by the statistical material; $T_{y k}$ is the annual working days of the container yard; $N_{l}$ is the stacking height of the containers, determined by the yard equipment; $A_{s}$ is the capacity utilization of the container yard.

(2) The length of the yard $B$ generally is equivalent to the length of the container terminal, and it is determined 


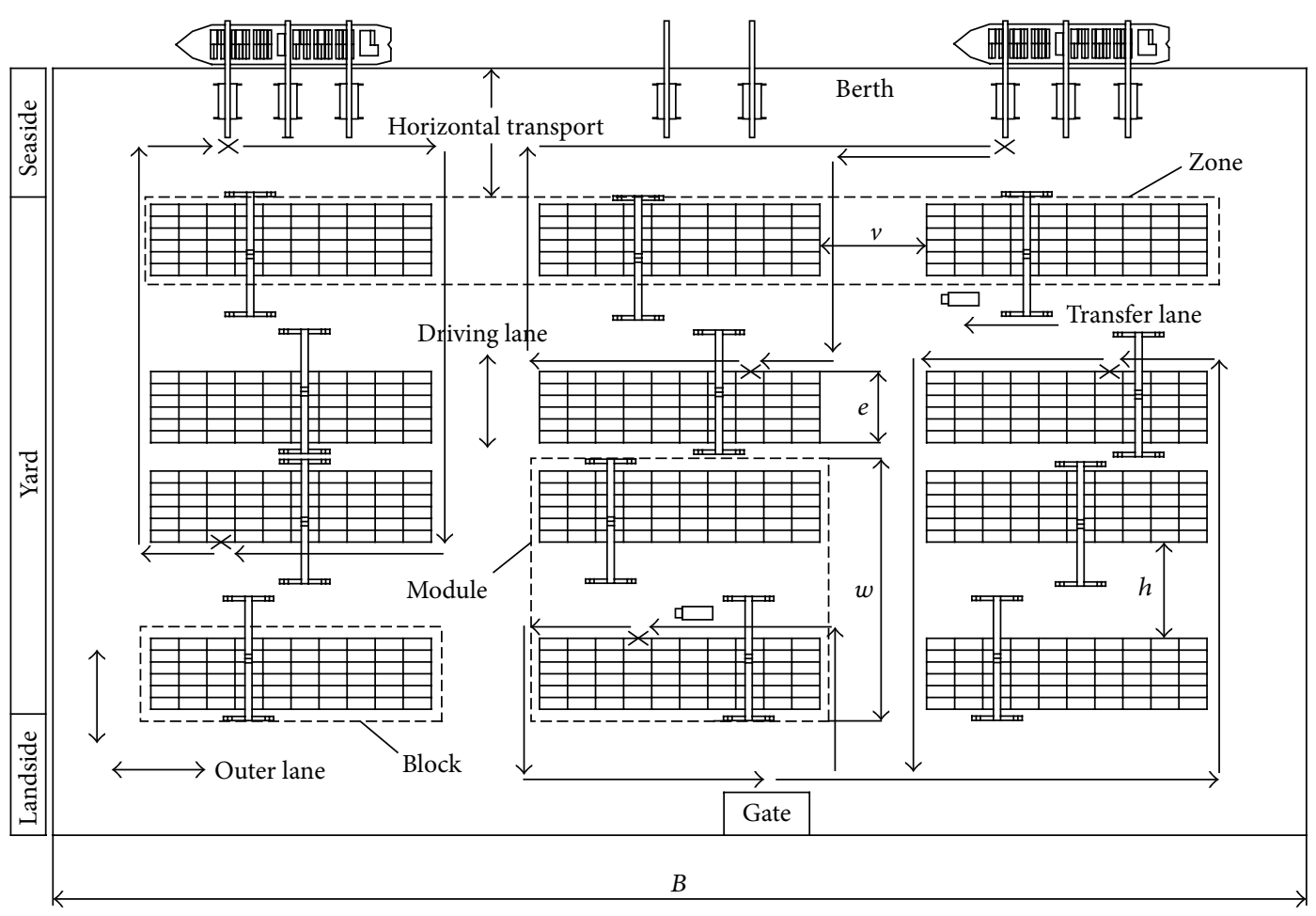

FIGURE 1: Typical layout of a parallel container terminal.

mainly by the coastline, the total amount of the berths, and the tonnage of the containerships.

(3) The depth of the yard $A$ should be determined by the design container traffic volume and the handling technology of the container terminal, and it is expressed as

$$
A=\frac{1}{2} M(2 e+h)+2 v
$$

where $M$ is the number of rows of blocks in the yard layout; $e$ is the width of a block, determined by the yard equipment; $h$ and $v$ are the width of a transfer lane and driving lane, respectively.

(4) The length of yard block $l$ is selected taking into account rational service radius of the handling equipment. Based on the layout of berth and yard, $l$ is suitable between 200 and 300 meters, and it can be expressed as

$$
l=\frac{B-(N+1) v}{N}
$$

where $N$ is the number of columns of blocks in the yard layout.

(5) There are no detailed procedures to determine the quantity of yard cranes deployed at the terminal. It can be found from several engineering projects in operation and under construction that the number of deployed yard cranes is generally 2 4 times of quay cranes.
Therefore, selections of the number of rows of blocks, the number of columns of blocks, and the number of yard cranes deployed are the key to determining the yard layout. These three decisions interact with each other and cause several trade-offs in the system. For example, a large number of rows of blocks bring higher capital investment but result in a lower number of relocations during retrieval operations due to the reduced stacking height. Similarly, a larger number of columns of blocks (equivalently, a larger number of driving lanes) bring a shorter travel distance for trucks but reduce the ground space for stacking containers, which then increase the stacking height. In this paper, systems approach is necessary to capture the interactions of various design variables simultaneously.

2.2. Yard Design under Uncertainty. The global maritime logistics market contains various uncertainties that inherit from the fluctuation of the demand for freight transportation. Influenced by terminal scale, freight organization, truck and ship operation, natural conditions, and production management, terminal production shows unbalance response, evident by collected real data of a variety of ports in China [9]. The monthly throughput of the container terminal generally has a long-term variation trend and seasonal fluctuations [28, 29]. Therefore, the randomness contained in the container terminal logistics system has brought new challenges for making a cost-effective and reliable yard design so as to support sustainable development of the terminal infrastructure. 
There are three basic programming methods dealing with uncertainty, that is, stochastic, fuzzy, and interval programming. The main difference lies in the modeling method of uncertainty. Uncertainty is described by discrete or continuous probability distribution function in stochastic programming. In fuzzy programming, uncertainty and constraint are treated as fuzzy number and fuzzy set, respectively. A certain extent of constraint being not satisfied is allowed, and the satisfaction degree is defined as membership function of the constraint. In interval programming, value range of uncertainty is denoted in the form of interval numbers. Interval programming is a relatively new research field and direction, and there are still a lot of issues to be resolved. The research on fuzzy linear programming is mature but that on fuzzy nonlinear programming needs further study. The theory and application of stochastic programming are mature though it is difficult to get the precise probability distribution from the actual problem.

The monthly container throughput $\xi$ (TEU/month) is considered as an uncertain parameter in this study. With historical data and the projection for future economy, a longterm variation trend and seasonal fluctuation of $\xi$ can be obtained (see $[28,29]$ for details). Since this is a complex process and not the main issue of this paper, we assume such information as given; that is, discrete $\xi$ is described by a set of scenarios and their associated probabilities. With this information and in view of the nonlinear characteristics, we choose stochastic programming, the mature and convenient programming method, to deal with uncertain throughput.

Two-stage stochastic programming separates the a priori planning decisions, taken under uncertainty before the activity cycle starts, and the adjustments performed at each period of operations once information becomes available. The former makes up the first stage of the model, while the recourse actions, defining the admissible adjustments to the plan, make up the second stage. The lead time of container yard is not short. In the process of yard design under uncertain environment, planning decisions, such as yard size and the equipment deployment, need to be made in the planning stage before the uncertain throughput is revealed. These decisions are usually capital intensive and cannot be easily adjusted once implemented. For a designed container yard with certain capacity, the required space is sometimes higher than the provided space during the real operation. In such a situation, extra space will be required (e.g., stacking surplus containers in an adjacent yard or rental space from an off-dock yard), resulting in a recourse cost due to overcapacity. Operational decisions, such as the amount of containers stacked in and out of the designed yard, can be adjusted (with a recourse cost) depending on the actual realization of uncertain future throughput. To distinguish different natures of planning and operational decisions, we choose to develop a two-stage stochastic programming with recourse model [30], which has been successfully used in logistics planning [31]. This model can well describe the planning and operation stages of container yard and recognize the nonanticipativity of planning decisions while allowing recourse for operational decisions.

\section{Methodologies}

3.1. Optimization Model. The yard design optimization problem is stated as follows: which yard layout is chosen under given investment budget constraints to minimize the sum of capital cost and operation losses considering uncertain terminal throughput? In this model, the number of rows of blocks $M$, the number of columns of blocks $N$, and the number of yard cranes per row of blocks $n$ are firststage decision variables, while the throughput of containers that will be stacked in or out of the designed yard $y(\xi)$ and $\omega(\xi)$ are second-stage decision variables. The proposed model addressing the yard design optimization problem is formulated as

$$
\min \quad C_{M, N, n}=C_{\text {cap }}+E_{\xi} C_{\text {ope }}
$$

subject to

$$
\begin{aligned}
& \frac{M}{2}, N, n \in Z_{+}, \\
& C_{\text {cap }} \leq B_{\text {cap }}, \\
& y \leq V, \\
& y+\omega=\xi, \\
& y, \omega \geq 0,
\end{aligned}
$$

where $C_{\text {cap }}$ is the capital cost of the proposed container yard; $E_{\xi}$ denotes mathematical expectation with respect to $\xi ; B_{\text {cap }}$ is the expected investment budget and $C_{\text {ope }}$ is the operation losses of trucks travelling and yard cranes moving during the process of achieving the throughput $\xi$. Constraint (5) simply restricts $M / 2, N$, and $n$ to be positive integer. Constraint (6) represents the investment budget constraint. Constraint (7) sets the capacity restriction, where $V$ is a predefined maximum capacity which is determined by $M, N$, and the maximum stacking height. Constraint (8) requires that all containers must be stored, whether at the designed yard area or its neighboring yards or off-dock yards. Constraint (9) simply restricts $y, \omega$ to be nonnegative.

3.1.1. Capital Cost $C_{\text {cap }}$. Initial investment is used for the cost of yard space and the purchasing of yard cranes. The total capital cost is written as follows:

$$
C_{\text {cap }}=c_{a} a+c_{f} n M
$$

where $c_{a}$ is the capital cost for unit area of yard per month, including the land fee and construction cost $\left(\mathrm{CNY} / \mathrm{m}^{2} / \mathrm{month}\right) ; a$ is the required area of the container yard; for given $M, a$ can be calculated by $a=(e M+0.5 h M+$ $2 h) B$ (see Figure 1 ); $c_{f}$ is the fixed cost of a yard crane per month (CNY/month).

3.1.2. Operation Losses $C_{\text {ope }}$. If the space of the yard or the quantity of yard cranes deployed is not adequate, the operational cost of containers stacked in and out of the designed 
yard area (denoted by $c_{\text {in }}$ and $c_{\text {out }}$, resp.) will be increased. The operation losses can be considered as the recourse cost quantifying the effectiveness of the first-stage decision. Three categories of containers, namely, the import, export, and transit containers, are considered. Import containers flow from containerships to the storage yard by internal trucks for temporary storage and then are picked up by external trucks to the customers. Export process is opposite from import process. Transit containers flow from one containership to the yard and will be loaded into another ship later on. Internal trucks are designated for single berth instead of the whole terminal. They deliver containers in a single-cycle mode, in which they repeat a loaded-then-empty travel, alternately, between transfer positions under quay cranes and storage sites in the yard. Therefore, the losses are formulated as

$$
\begin{aligned}
C_{\text {ope }}= & \min _{y, \omega}\left\{c_{\text {in }} \gamma y+c_{\text {out }} \gamma \omega\right\}, \\
c_{\text {in }}= & 2 c_{r} t_{t} d+2 c_{r} t_{h}+c_{r} t_{r} R+\beta\left(2 c_{\mathrm{it}} t_{\mathrm{it}} d_{b}\right) \\
& +(1-\beta)\left(c_{\mathrm{it}} t_{\mathrm{it}} d_{b}+c_{\mathrm{et}} t_{\mathrm{et}} d_{g}\right),
\end{aligned}
$$

where $\gamma$ is the factor that converts TEUs into a number of containers; $c_{r} t_{t} d$ denotes the travel time cost of the yard crane per move $\left(c_{r}\right.$ is the variable cost of a yard crane per second $(\mathrm{CNY} / \mathrm{s}) ; t_{t}$ is the travel time of yard crane per meter $(\mathrm{s} / \mathrm{m}) ; d$ is the average travel distance of the yard crane between moves); $c_{r} t_{h}$ is the cycle time cost of the yard crane handling a container $\left(t_{h}\right.$ is the cycle time required for the handling of a container (s)); $c_{r} t_{r} R$ means the relocation cost of the yard crane ( $t_{r}$ is the time required for the relocation of a container (s); $R$ is the average number of rehandles for picking up an arbitrary container out of a bay); $\beta$ is the proportion of transit containers among all containers; $2 c_{\mathrm{it}} t_{\mathrm{it}} d_{b}$ represents the transport cost for a transit container, which is transported by internal trucks twice during its stay at the terminal ( $c_{\text {it }}$ is the cost of an internal truck per second, including the overhead cost and the operating cost (costs for labour, fuel, and maintenance) $(\mathrm{CNY} / \mathrm{s}) ; t_{\text {it }}$ is the travel time of internal trucks per meter $(\mathrm{s} / \mathrm{m}) ; d_{b}$ is the average travel distance between the berth and yard); similarly, $c_{\mathrm{it}} t_{\mathrm{it}} d_{b}+$ $c_{\text {et }} t_{\text {et }} d_{g}$ is the transport cost for each import/export container $\left(c_{\text {et }}\right.$ is the cost of an external truck per second, including the overhead cost and the operating cost (costs for labour, fuel, and maintenance) $(\mathrm{CNY} / \mathrm{s}) ; t_{\mathrm{et}}$ is the travel time of external trucks per meter $(\mathrm{s} / \mathrm{m}) ; d_{g}$ is the average travel distance between the gate and yard).

For a bay of 6 stacking lanes of containers, suppose that the relocation of containers is restricted to a single bay and that pre-schedule for reducing relocations is ignored; the expected number of relocations $R$ then can be evaluated by the following formula [32]:

$$
R=\frac{2 T-1}{4}+\frac{T+1}{48},
$$

where $T$ is the average stacking height, which can be calculated as follows:

$$
\begin{aligned}
T & =\frac{y t_{d c}}{t_{y k} G A_{s}} \\
G & =\frac{e M B-e M v(N+1)}{s},
\end{aligned}
$$

where $t_{y k}$ is the monthly operational days of container yard (day); $G$ is the number of ground slots for stacking containers; $A_{s}$ is the capacity utilization of the container yard, which is between 0 and 1 because of some unused space for the requirement of relocations; $s$ is the space required for a TEU, including the allowance between containers $\left(\mathrm{m}^{2}\right)$.

In the optimization model, the average travel distance of the yard crane between moves $(d)$ and the average travel distance between berth and yard $\left(d_{b}\right)$ and between gate and yard $\left(d_{g}\right)$ are the key to calculating the values of the objective function. However, since the container terminal logistics system is a stochastic dynamic service system with multiple random factors and complex dynamic relations [33], these indicators are hard to be derived from the conventional analytical method and thus they will be computed by the incorporation of simulation models descried in the following section.

3.2. Model Framework. Figure 2 presents the proposed simulation-based optimization framework to optimize container yard design concerning throughput uncertainty. It can be seen that the framework is composed of a two-stage stochastic programming (TSSP) model and a simulation model of terminal operations (SMTO). In the framework, the TSSP generates feasible yard design schemes, transfers it to the SMTO, and evaluates the total cost. The SMTO emulates the container flow at mega terminal, outputs the values of $d$, $d_{b}$, and $d_{g}$, and returns the simulation results to the TSSP. Therefore, the core of this framework is the TSSP aided with the SMTO.

3.2.1. Optimization Program. As illustrated in Figure 2, the solution procedure of the TSSP consists of the following steps in sequence.

(1) Input Data Generation. Inputs include uncertain container throughput, terminal handling technology, terminal operational parameters, and cost coefficients.

Uncertain container throughput is expressed by the random vector $\xi(s)$ depending on the scenario $s(s=1,2, \ldots, S)$ with associated probabilities $p(s)(p(1)+p(2)+\cdots+p(S)=1)$. Information about $\xi(s)$ and $p(s)$ can be drawn based on the historical data and the projection for future economy, which is not the main concern in this paper.

Yard handling technology includes the type and span width of the yard crane and the width of a transfer lane and a driving lane, which can be determined by the MTPRC and practical design handbooks.

Yard operational parameters include monthly operational days, the average cluration of containers, the maximum 


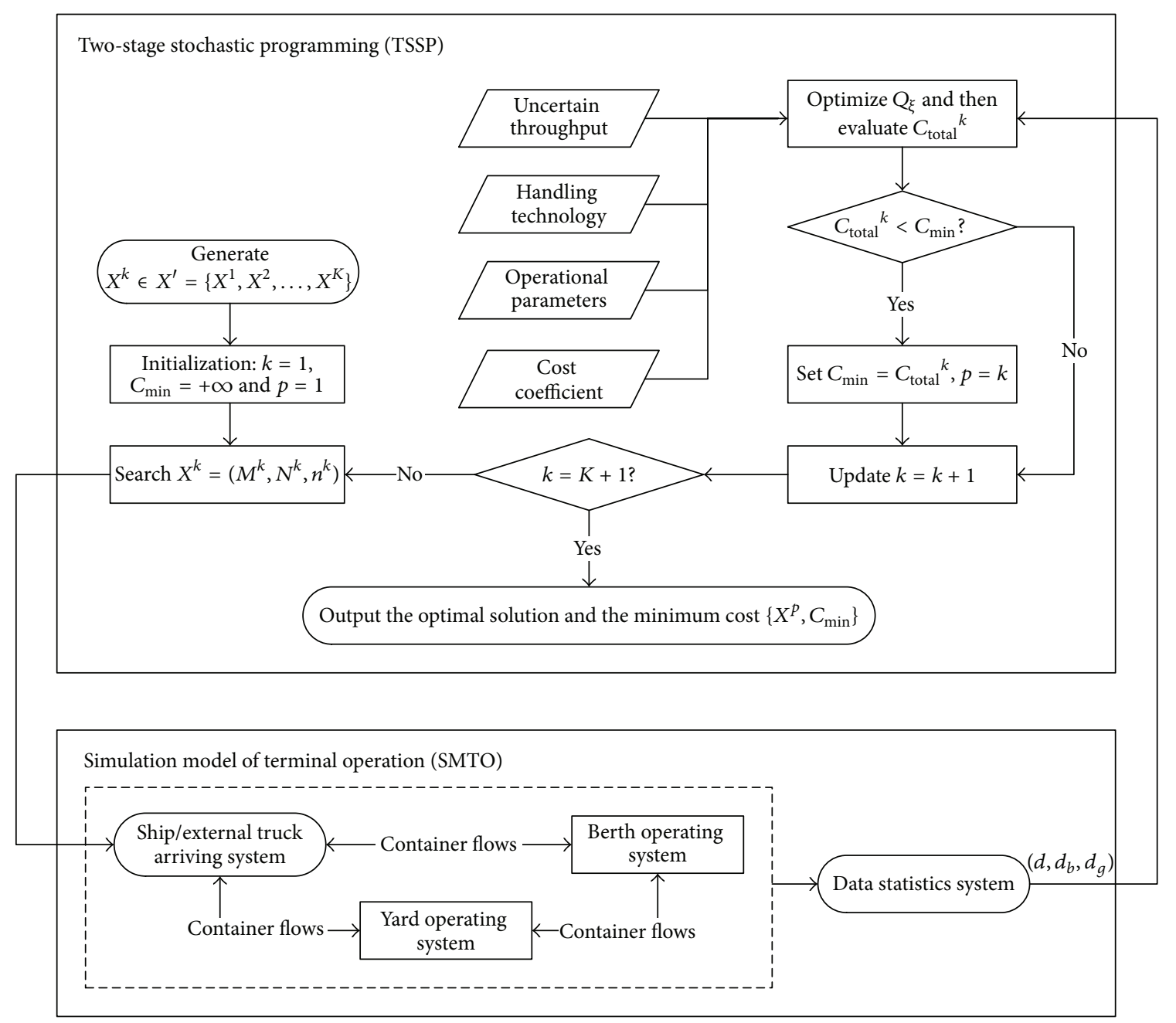

FIGURE 2: The simulation-based optimization framework for yard design at mega container terminal.

stacking height, the average moving speed of yard crane, and the average running speed of trucks.

Cost coefficients involve the unit space cost, the capital cost for the yard crane, and variable operational costs associated with the yard crane and trucks. These cost coefficients generally can be provided by the potential terminal operator or through field investigation.

(2) Feasible Solution Set Delimitation. The possible yard design schemes $X^{\prime}$ are enumerated by calculating all combinations of possible block quantities (measured in $M$ and $N$ ) and yard crane amount $n$, and all feasible solutions are numbered in order for searching; that is, $X^{k}=\left(M^{k}, N^{k}, n^{k}\right)$ belongs to $X^{\prime}=\left\{X^{1}, X^{2}, \ldots, X^{K}\right\}$.

(3) Initialization. Set $k=1$; the minimum total costs $C_{\min }=$ $+\infty$ and the corresponding index of solution in the set $p=1$.

(4) Simulation Activation and Objective Function Evaluation. Search the feasible solution $X^{k}$. Transfer $X^{k}$ to the SMTO, run the simulation model to get $d, d_{b}$, and $d_{g}$, and return them to the TSSP. Optimize the second-stage model of the TSSP, and obtain the optimal $Q$ as well as the corresponding decision variables $y$ and $\omega$ under uncertain throughput $\xi$. Evaluate the objective function $C_{\text {total }}{ }^{k}$, that is, the sum of the first-stage and expected second-stage costs.

(5) Optimization and Decision. If $C_{\text {total }}{ }^{k}<C_{\min }$, set $C_{\min }=$ $C_{\text {total }}{ }^{k}$ and $p=k$. Update $k=k+1$. If the termination criterion is satisfied, that is, $k=K+1$, stop and output the optimal design scheme and its corresponding minimum cost $\left\{X^{p}, C_{\min }\right\}$; otherwise go to step (4).

3.2.2. Simulation Model. A process interaction-based discrete event simulation model is developed for terminal operations via commercial software Arena 10.0, and it is verified and validated before running productive simulations [34]. According to the operational processes as outlined in Figure 3, the simulation model consists of five systems as follows.

(1) Ship/external truck arriving system: ships are created and initialized in accordance with the shipping schedule and the handling plan. The processes of 


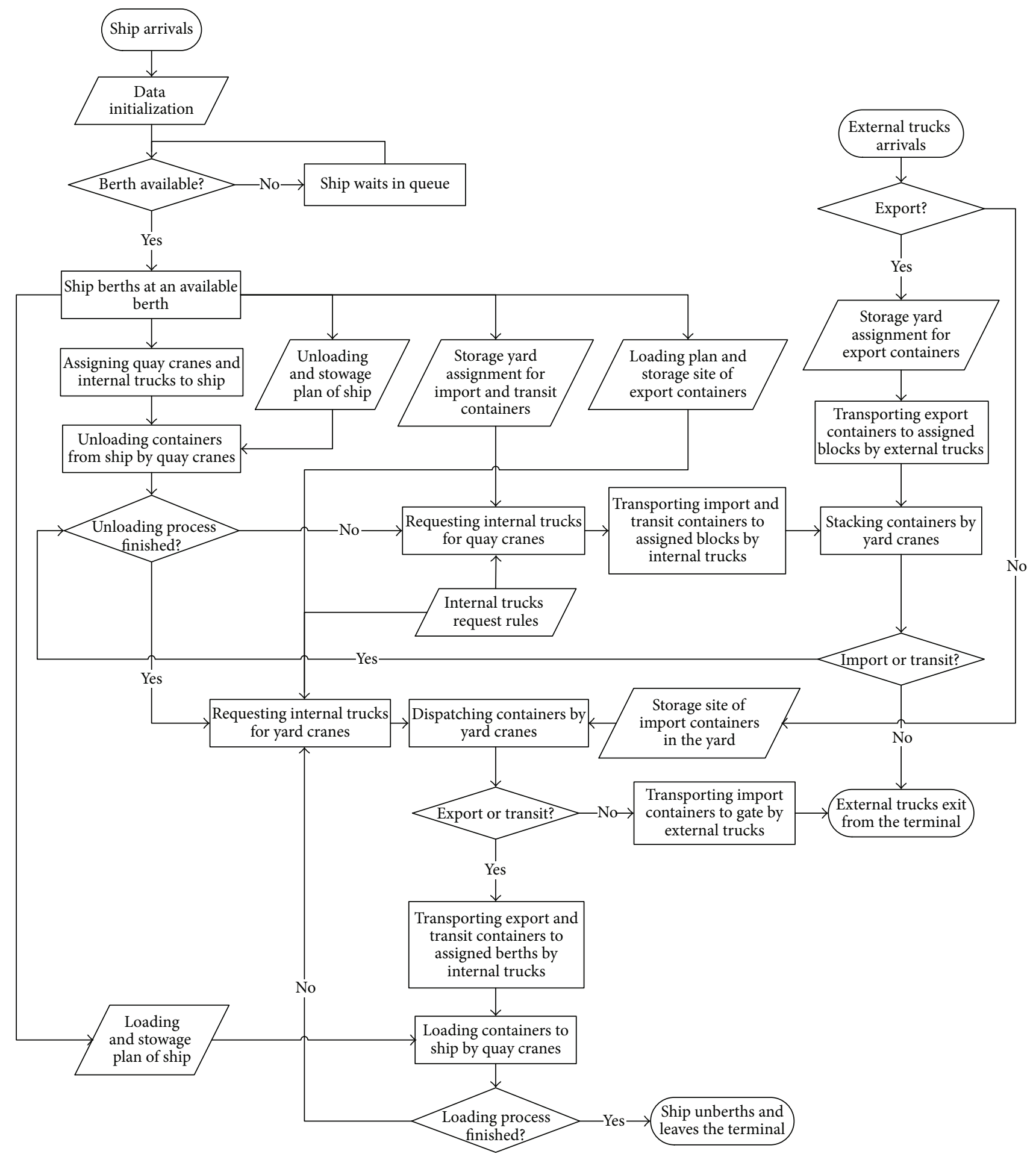

FIgURE 3: The logic flowchart of container terminal operation.

berth allocation and external trucks picking up and delivering containers are triggered, respectively.

(2) Berth operating system: ships begin to receive unloading and loading service after berthing and preparatory work. Internal trucks are designated equally among the quay cranes assigned to the corresponding ship. The operations of quay cranes coordinating with internal trucks are simulated.

(3) Yard operating system: import, export, and transit containers realize stockpiling and extracting by handling equipment in designate section of the yard according to the stacking plan. Yard cranes are 


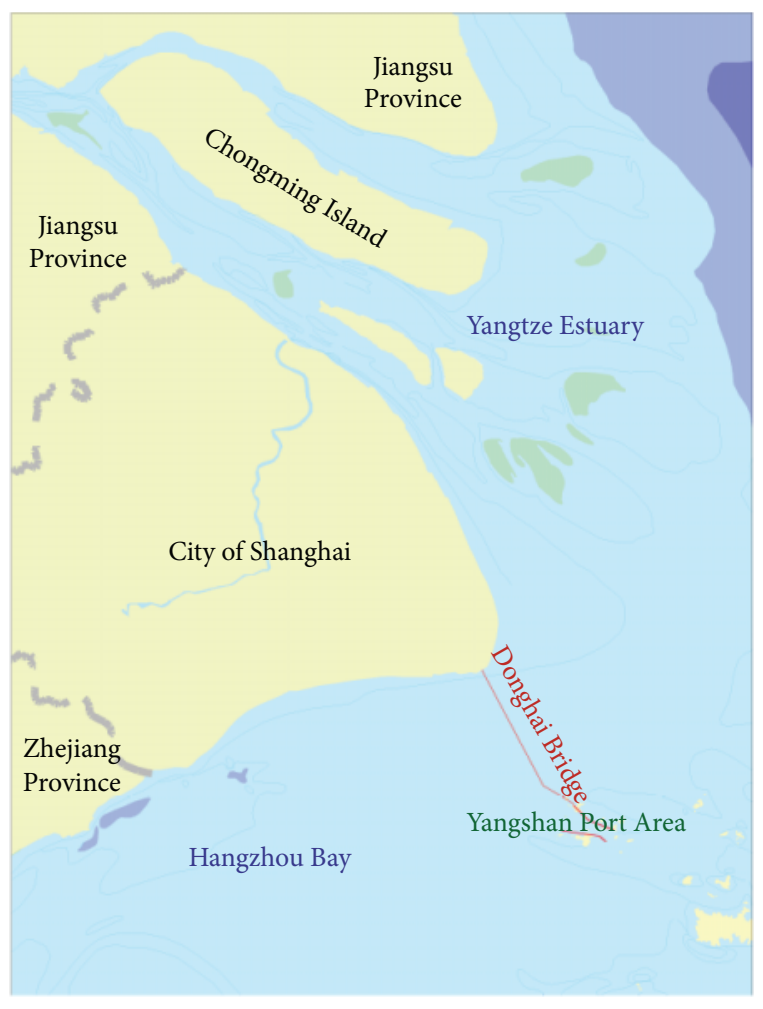

FIgURE 4: Sketch of location of Yangshan Port Area.

assigned to each zone of the container yard, preventing the gantry move of yard crane in different zones. Internal and external truck streamlines converge here, and the next station of trucks will be the gate or berth corresponding to their different tasks.

(4) Assignment generating system: both the loading and unloading plan of each ship and the storage yard assignment for corresponding import, export, and transit containers are generated.

(5) Data statistics system: the above four systems work independently and interact with each other by container flows. Yard crane and truck information is recorded and the average travel distance of yard crane between moves and the average travel distances of internal trucks and external trucks can be calculated and transferred to the optimization program.

\section{Case Study}

The framework is applied to the second phase terminal (hereafter referred to as Phase II Terminal) of Shanghai Yangshan Port Area in China as a case study. With an aim to become an international shipping center, Shanghai City has selected Yangshan as the site for its deep-water terminals; see Figure 4. The construction of container terminals in this port area is implemented in four phases. Phase II Terminal, possessing a total of 1,400 meters coastline, is equipped with four container berths which can accommodate containerships over 8,000 TEUs. The land area of the yard

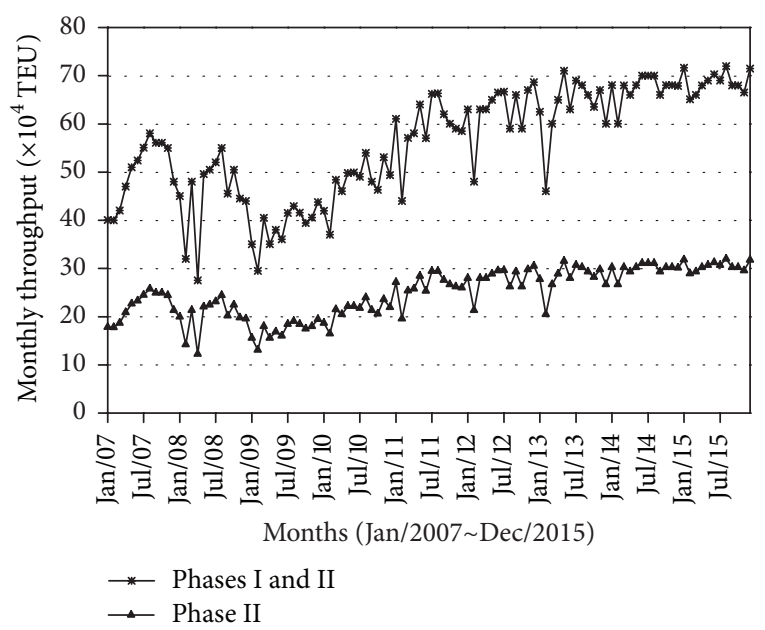

FIgure 5: Monthly throughput of Phase I and Phase II Terminals.

at the terminal is reclaimed from the sea and not easy to be adjusted during the operational period. Therefore, due to the huge investment, economic and sustainable pressures have acknowledged the need not only to minimize the initial investment but also to ensure the terminal efficiency and reliability when determining the yard design.

4.1. Model Input. The monthly throughput data of Phase I and Phase II Terminal (two terminals have been merged in real operation since Phase II Terminal went into operation) from 2007 to 2015 are provided by China Ports and Harbours Association, as plotted in Figure 5. The monthly throughput of Phase II Terminal is estimated assuming it is proportional to the length of the terminal. 108 monthly throughputs are used to construct a set of discrete scenarios with equal probabilities in this case study.

Input data of the proposed optimization framework for this container terminal are provided as shown in Table 1 [9, 35].

This study evaluates 6 options for the initial monthly investment budgets, including $5 \mathrm{MCNY}$ (Million CNY), 5.5 MCNY, 6 MCNY, 6.5 MCNY, 7 MCNY, and 7.5 MCNY, to be investigated.

Based on the geographical location of Phase II Terminal and field investigation, we set a relatively high recourse cost: the operation cost of storing a container out of the designed yard is 10 times the value of a container stacked in the designed yard area.

4.2. Results and Discussions. Table 2 shows the optimal yard design schemes under various investment budget constraints by the proposed optimization framework. As listed in Table 2, the optimal decision with the initial monthly investment budget of at least $7 \mathrm{MCNY}$ (in fact, the investment cost calculated is $6.57 \mathrm{MCNY}$ ) is 14 rows and 6 columns of blocks and 3 yard cranes deployed in each zone of blocks. The corresponding yard design scheme of yard depth, block length, and amount of yard cranes are $413 \mathrm{~m}, 210 \mathrm{~m}$, and 42, respectively. 
TABLE 1: Input data of the proposed optimization framework for this container terminal.

\begin{tabular}{|c|c|c|}
\hline Items & Unit & Data input \\
\hline (1) Simulation time & Hour & $30 \times 24$ \\
\hline \multicolumn{3}{|l|}{ (2) Uncertain throughput } \\
\hline (i) Random vector with associated probability, $\xi(s), p(s)$ & & See Figure 5 \\
\hline \multicolumn{3}{|l|}{ (3) Yard handling technology } \\
\hline (i) Maximum span width of yard crane & Meter & 23.47 \\
\hline (ii) Block width, $e$ & Meter & 16.63 \\
\hline (iii) Width of transfer lane and driving lane, $h, v$ & Meter & 20 \\
\hline (iv) Space required for a TEU, $s$ & Square meter & 17.63 \\
\hline \multicolumn{3}{|l|}{ (4) Yard operational parameters } \\
\hline (i) Monthly operational days, $t_{y k}$ & Day & 30 \\
\hline (ii) Capacity utilization, $A_{s}$ & & 0.7 \\
\hline (iii) Average cluration of containers, $t_{d c}$ & Day & 5.5 \\
\hline (iv) Maximum stacking tiers & & 5 \\
\hline (v) Travel time of yard crane per meter, $t_{t}$ & Second/meter & 0.45 \\
\hline (vi) Cycle time required for handling a container, $t_{h}$ & Second & 77.1 \\
\hline (vii) Average relocation time, $t_{r}$ & Second & 74.2 \\
\hline (viii) Travel time of trucks per meter, $t_{\mathrm{it}}, t_{\mathrm{et}}$ & Second/meter & 0.18 \\
\hline \multicolumn{3}{|l|}{ (5) Cost coefficients } \\
\hline (i) Capital cost for yard space, $c_{a}$ & $\mathrm{CNY/square} \mathrm{meter/month}$ & 8.33 \\
\hline (ii) Capital cost for yard crane, $c_{f}$ & $\mathrm{MCNY} / \mathrm{month}$ & 0.042 \\
\hline (iii) Variable cost for yard crane, $c_{r}$ & $\mathrm{CNY} /$ second & 0.053 \\
\hline (iv) Variable cost for truck, $c_{\mathrm{it}}, c_{\mathrm{et}}$ & $\mathrm{CNY} /$ second & 0.023 \\
\hline \multicolumn{3}{|l|}{ (6) Investment budgets } \\
\hline (i) Options, $B_{\text {cap }}$ & MCNY & $5,5.5,6,6.5,7,7.5$ \\
\hline
\end{tabular}

Moreover, from an engineering perspective, the following observations are made.

(1) Optimal yard design schemes change as the investment budget varies. For example, if the monthly budget is less than $6 \mathrm{MCNY}, 360 \mathrm{~m}$ yard depth with higher block length and less yard cranes deployed is preferred. However, the optimal yard design scheme will not change when the monthly budget is between $6 \mathrm{MCNY}$ and 6.5 MCNY or greater than $7 \mathrm{MCNY}$, as shown in Table 2. It is noted that more budgets would not always obtain extra profits; therefore, investors should pay more attention to these situations to avoid unnecessary investment.

(2) The investment budget has a negative correlation with the losses from yard operation in a certain scope. As shown in Figure 6, when the initial monthly investment budget increases from $5 \mathrm{MCNY}$ to 7 MCNY, the operation losses will decrease from 11.01 MCNY to 6.19 MCNY, and the gained benefit is about $44 \%$ equivalently. Therefore, if the investment budget is adequate, larger depth yard with less block length and more yard cranes deployed is favourable for improving operation efficiency and reducing operation losses.

(3) Large quantity of yard cranes deployed at the container terminal results in a higher investment cost but lower operation losses. However, for certain layout of

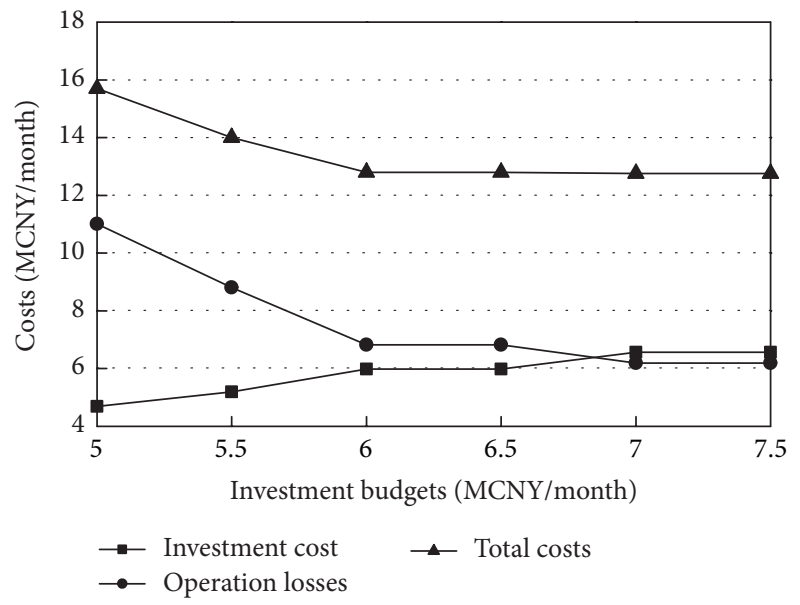

Figure 6: The costs of optimal yard design scheme for various investment budgets.

the yard (with given yard depth and block length), the variations of yard cranes deployed may not affect the total costs significantly. As shown in Table 2, for a yard layout with $413 \mathrm{~m}$ depth and $210 \mathrm{~m}$ block length, the number of yard cranes deployed increases from 28 to 42 , resulting in the investment cost increasing from 5.98 MCNY to 6.57 MCNY, but the operation losses decreasing from 6.82 MCNY to 6.19 MCNY, and the total costs being stable at about $12.8 \mathrm{MCNY}$. In this 


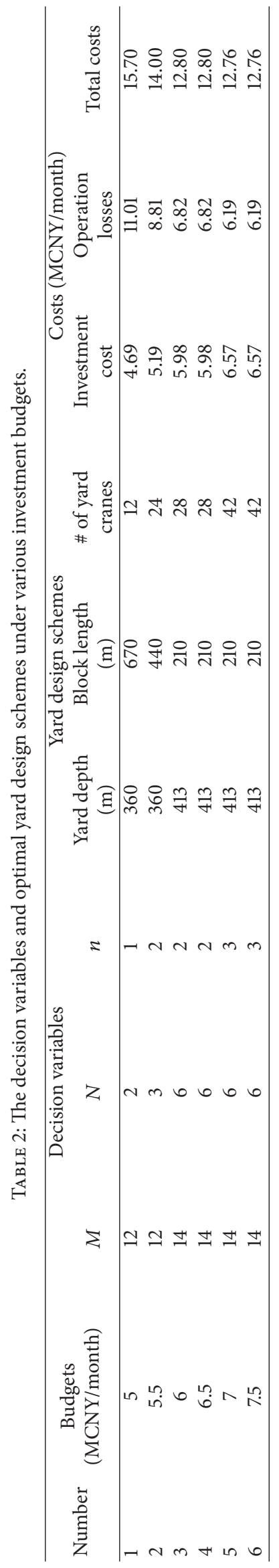


TABLE 3: The feasible yard design schemes determined by MTPRC under various investment budgets.

\begin{tabular}{|c|c|c|c|c|c|c|c|c|c|c|}
\hline \multirow{2}{*}{ Number } & \multirow{2}{*}{$\begin{array}{c}\text { Budgets } \\
(\mathrm{MCNY} / \mathrm{month})\end{array}$} & \multicolumn{3}{|c|}{$\begin{array}{l}\text { Decision } \\
\text { variables }\end{array}$} & \multicolumn{3}{|c|}{ Yard design schemes } & \multicolumn{3}{|c|}{ Costs (MCNY/month) } \\
\hline & & $M$ & $N$ & $n$ & $\begin{array}{l}\text { Yard depth } \\
\quad(\mathrm{m})\end{array}$ & $\begin{array}{c}\text { Block length } \\
(\mathrm{m})\end{array}$ & $\begin{array}{c}\text { \# of yard } \\
\text { cranes }\end{array}$ & $\begin{array}{l}\text { Investment } \\
\text { cost }\end{array}$ & $\begin{array}{l}\text { Operation } \\
\text { losses }\end{array}$ & Total costs \\
\hline 1 & 5 & & & & & & & & & \\
\hline 2 & 5.5 & 14 & 5 & 1 & 413 & 256 & 14 & 5.40 & 8.76 & 14.16 \\
\hline 3 & 6 & 14 & 5 & 1 & 413 & 256 & 14 & 5.40 & 8.76 & 14.16 \\
\hline 4 & & 14 & 5 & 2 & 413 & 256 & 28 & 5.98 & 6.87 & 12.85 \\
\hline 5 & 6.5 & 14 & 5 & 1 & 413 & 256 & 14 & 5.40 & 8.76 & 14.16 \\
\hline 6 & & 14 & 5 & 2 & 413 & 256 & 28 & 5.98 & 6.87 & 12.85 \\
\hline 7 & & 16 & 5 & 1 & 466 & 256 & 16 & 6.10 & 8.65 & 14.75 \\
\hline 8 & & 16 & 6 & 1 & 466 & 210 & 16 & 6.10 & 8.59 & 14.69 \\
\hline 9 & 7 & 14 & 5 & 1 & 413 & 256 & 14 & 5.40 & 8.76 & 14.16 \\
\hline 10 & & 14 & 5 & 2 & 413 & 256 & 28 & 5.98 & 6.87 & 12.85 \\
\hline 11 & & 14 & 5 & 3 & 413 & 256 & 42 & 6.57 & 6.24 & 12.81 \\
\hline 12 & & 16 & 5 & 1 & 466 & 256 & 16 & 6.10 & 8.65 & 14.75 \\
\hline 13 & & 16 & 5 & 2 & 466 & 256 & 32 & 6.77 & 6.77 & 13.54 \\
\hline 14 & & 16 & 6 & 1 & 466 & 210 & 16 & 6.10 & 8.59 & 14.69 \\
\hline 15 & & 16 & 6 & 2 & 466 & 210 & 32 & 6.77 & 6.71 & 13.48 \\
\hline 16 & & 18 & 5 & 1 & 519 & 256 & 18 & 6.81 & 8.59 & 15.40 \\
\hline 17 & & 18 & 6 & 1 & 519 & 210 & 18 & 6.81 & 8.52 & 15.33 \\
\hline 18 & 7.5 & 14 & 5 & 1 & 413 & 256 & 14 & 5.40 & 8.76 & 14.16 \\
\hline 19 & & 14 & 5 & 2 & 413 & 256 & 28 & 5.98 & 6.87 & 12.85 \\
\hline 20 & & 14 & 5 & 3 & 413 & 256 & 42 & 6.57 & 6.24 & 12.81 \\
\hline 21 & & 14 & 5 & 4 & 413 & 256 & 56 & 7.15 & 5.93 & 13.08 \\
\hline 22 & & 16 & 5 & 1 & 466 & 256 & 16 & 6.10 & 8.65 & 14.75 \\
\hline 23 & & 16 & 5 & 2 & 466 & 256 & 32 & 6.77 & 6.77 & 13.54 \\
\hline 24 & & 16 & 5 & 3 & 466 & 256 & 48 & 7.44 & 6.14 & 13.58 \\
\hline 25 & & 16 & 6 & 1 & 466 & 210 & 16 & 6.10 & 8.59 & 14.69 \\
\hline 26 & & 16 & 6 & 2 & 466 & 210 & 32 & 6.77 & 6.71 & 13.48 \\
\hline 27 & & 16 & 6 & 3 & 466 & 210 & 48 & 7.44 & 6.08 & 13.52 \\
\hline 28 & & 18 & 5 & 1 & 519 & 256 & 18 & 6.81 & 8.59 & 15.40 \\
\hline 29 & & 18 & 6 & 1 & 519 & 210 & 18 & 6.81 & 8.52 & 15.33 \\
\hline
\end{tabular}

case, if the investment budget is allowed, more yard cranes are suggested to be deployed so as to better serve the terminal operation but with no increase in the total costs.

Table 3 lists several feasible yard design schemes determined by given investment budgets according to the MTPRC and practical handbooks which use a single container throughput and an unbalance factor (see Section 2). As shown in Table 3, no feasible solution can be obtained to ensure the storage capacity of the yard under the monthly investment budget of $5 \mathrm{MCNY}$. When the budget is greater than $5 \mathrm{MCNY}$, we have various feasible solutions of yard design schemes. For example, if the budget is $7 \mathrm{MCNY}$, there are nine alternatives available. However, both the MTPRC and practical handbooks do not give the quantitative method of determining the better choice, and it is difficult for the designers to choose without a specific mathematical optimization model. Here we use the proposed SMTO to get the operation losses of these feasible yard schemes, and the proposed optimization model is also adopted to choose the good yard design schemes from the alternatives, as listed in Table 3. It can be found that number 11 scheme is the better choice for the budget of 7 MCNY. Therefore, the proposed simulation-based optimization framework is effective in optimizing yard design schemes and reducing planned initial investment budgets, which is a helpful decision-making tool for both terminal investors and governmental agencies.

\section{Summary and Conclusions}

This paper is a new endeavour in yard design at mega container terminals concerning throughput uncertainty. Using a developed integrated decision framework which is composed 
of a two-stage stochastic programming model and a simulation model of terminal operations, we are able to obtain a cost-effective and reliable design solution to the layout and equipment deployment strategy of a container yard. The real-world case study demonstrates the applicability of the proposed framework and the value of incorporating risks in the early stage of infrastructure planning.

We are still in an early stage of this research where our focus is mainly on proposing effective methodologies and finding the optimal solutions for normal operations of mega container terminals. The precise identification of a representative set of uncertain throughput scenarios requires knowledge and experience of past or similar container terminals, which needs some work in the future study. Moreover, port facilities are generally considered as critical infrastructure, which plays an important role in regional and global economy. How to plan the infrastructure to protect it against extreme risks is a worthy research topic. Another potential extension is to incorporate multiple performance measures such as emission and energy consumption in the design objective to address pressing issues on sustainability.

\section{Competing Interests}

The authors declare that they have no competing interests.

\section{Acknowledgments}

The authors would like to greatly thank helpful comments provided by Professor Yueyue Fan of Civil and Environmental Engineering at University of California, Davis (USA). Financial support from the National Natural Science Foundation of China [Grants nos. 51279026 and 51309049] is gratefully acknowledged.

\section{References}

[1] UNCTAD, Review of Maritime Transport 2015, UNCTAD/RMT/2015, UNCTAD, United Nations Publication, 2015, http://unctad.org/en/PublicationsLibrary/rmt2015_en.pdf.

[2] L. Zhen, "Container yard template planning under uncertain maritime market," Transportation Research Part E, vol. 69, pp. 199-217, 2014.

[3] A. G. N. Novaes, B. Scholz-Reiter, V. M. D. Silva, and H. Rosa, "Long-term planning of a container terminal under demand uncertainty and economies of scale," Pesquisa Operacional, vol. 32, no. 1, pp. 55-85, 2012.

[4] UNCTAD, Review of Maritime Transport 2010, UNCTAD/ RMT/2010, UNCTAD, United Nations Publication, 2010, http:// www.unctad.org/en/docs/rmt2010_en.pdf.

[5] L. Chen, Risk Analysis Theory and Method for Project Investment, China Machine Press, Beijing, China, 2004.

[6] D. Chang, Z. Jiang, W. Yan, and J. He, "Integrating berth allocation and quay crane assignments," Transportation Research Part E: Logistics and Transportation Review, vol. 46, no. 6, pp. 975990, 2010.

[7] J. He, D. Chang, W. Mi, and W. Yan, "A hybrid parallel genetic algorithm for yard crane scheduling," Transportation Research Part E: Logistics and Transportation Review, vol. 46, no. 1, pp. 136-155, 2010.
[8] E. M. Alcalde, K. H. Kim, and S. S. Marchán, “Optimal space for storage yard considering yard inventory forecasts and terminal performance," Transportation Research Part E: Logistics and Transportation Review, vol. 82, pp. 101-128, 2015.

[9] Ministry of Transport of the People's Republic of China (MTPRC), "Design code of general layout for sea ports," Tech. Rep. JTS 165-2013, China Communications Press, Beijing, China, 2014.

[10] CCCC Water Transportation Planning and Design Institute Co. Ltd, Planning and Design of Modern Container Port Area, China Communications Press, Beijing, China, 2006.

[11] Z. Wang and X. He, "Research on the reasonable throughput capacity of container terminals," Port and Waterway Engineering, no. 3, pp. 16-20, 2004.

[12] S. P. Sgouridis, D. Makris, and D. C. Angelides, "Simulation analysis for midterm yard planning in container terminal," Journal of Waterway, Port, Coastal and Ocean Engineering, vol. 129, no. 4, pp. 178-187, 2003.

[13] C.-Y. Chu and W.-C. Huang, "Determining container terminal capacity on the basis of an adopted yard handling system," Transport Reviews, vol. 25, no. 2, pp. 181-199, 2005.

[14] P. Angeloudis and M. G. H. Bell, "A review of container terminal simulation models," Maritime Policy \& Management, vol. 38, no. 5, pp. 523-540, 2011.

[15] B. K. Lee, L. H. Lee, and E. P. Chew, "Analysis on container port capacity: a Markovian modeling approach," OR Spectrum, vol. 36, no. 2, pp. 425-454, 2014.

[16] K. H. Kim and H. B. Kim, "The optimal sizing of the storage space and handling facilities for import containers," Transportation Research Part B: Methodological, vol. 36, no. 9, pp. 821-835, 2002.

[17] K. G. Murty, J. Liu, Y.-W. Wan, and R. Linn, "A decision support system for operations in a container terminal," Decision Support Systems, vol. 39, no. 3, pp. 309-332, 2005.

[18] M. E. H. Petering, "Decision support for yard capacity, fleet composition, truck substitutability, and scalability issues at seaport container terminals," Transportation Research Part E: Logistics and Transportation Review, vol. 47, no. 1, pp. 85-103, 2011.

[19] C.-I. Liu, H. Jula, K. Vukadinovic, and P. Ioannou, "Automated guided vehicle system for two container yard layouts," Transportation Research Part C: Emerging Technologies, vol. 12, no. 5, pp. 349-368, 2004.

[20] J. Wiese, N. Kliewer, and L. Suhl, "A survey of container terminal characteristics and equipment types," Tech. Rep. 0901, DS\&OR Lab, University of Paderborn, Paderborn, Germany, 2009.

[21] M. E. H. Petering, "Effect of block width and storage yard layout on marine container terminal performance," Transportation Research Part E: Logistics and Transportation Review, vol. 45, no. 4, pp. 591-610, 2009.

[22] M. E. H. Petering and K. G. Murty, "Effect of block length and yard crane deployment systems on overall performance at a seaport container transshipment terminal," Computers and Operations Research, vol. 36, no. 5, pp. 1711-1725, 2009.

[23] K. H. Kim, Y.-M. Park, and M.-J. Jin, "An optimal layout of container yards," OR Spectrum, vol. 30, no. 4, pp. 675-695, 2008.

[24] N. Kemme, "Effects of storage block layout and automated yard crane systems on the performance of seaport container terminals,” OR Spectrum, vol. 34, no. 3, pp. 563-591, 2012.

[25] B. K. Lee and K. H. Kim, "Comparison and evaluation of various cycle-time models for yard cranes in container terminals," 
International Journal of Production Economics, vol. 126, no. 2, pp. 350-360, 2010.

[26] B. K. Lee and K. H. Kim, "Optimizing the block size in container yards," Transportation Research Part E: Logistics and Transportation Review, vol. 46, no. 1, pp. 120-135, 2010.

[27] B. K. Lee and K. H. Kim, "Optimizing the yard layout in container terminals,” OR Spectrum, vol. 35, no. 2, pp. 363-398, 2013.

[28] Y. Xiao, S. Wang, J. J. Liu, J. Xiao, and Y. Hu, “Throughput estimation based port development and management policies analysis," Maritime Policy \& Management, vol. 43, no. 1, pp. 8497, 2016.

[29] Y. Gao, M. Luo, and G. Zou, "Forecasting with model selection or model averaging: a case study for monthly container port throughput," Transportmetrica A: Transport Science, vol. 12, no. 4, pp. 366-384, 2016.

[30] J. R. Birge and F. Louveaux, Introduction to Stochastic Programming, Springer Series in Operations Research and Financial Engineering, Springer, New York, NY, USA, 2nd edition, 2011.

[31] D. Alem, A. Clark, and A. Moreno, "Stochastic network models for logistics planning in disaster relief," European Journal of Operational Research, vol. 255, no. 1, pp. 187-206, 2016.

[32] K. H. Kim, "Evaluation of the number of rehandles in container yards," Computers and Industrial Engineering, vol. 32, no. 4, pp. 701-711, 1997.

[33] C. A. Boer and Y. A. Saanen, "Improving container terminal efficiency through emulation," Journal of Simulation, vol. 6, no. 4, pp. 267-278, 2012.

[34] G. Tang, W. Wang, Z. Guo, X. Yu, and B. Wang, "Simulationbased optimization for generating the dimensions of a dredged coastal entrance channel," Simulation, vol. 90, no. 9, pp. 10591070, 2014.

[35] J. Wiese, L. Suhl, and N. Kliewer, "Mathematical models and solution methods for optimal container terminal yard layouts," OR Spectrum, vol. 32, no. 3, pp. 427-452, 2010. 


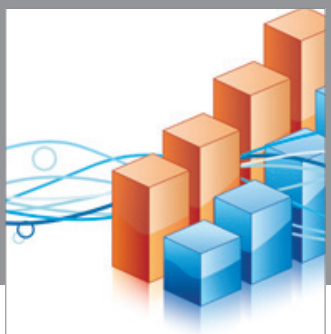

Advances in

Operations Research

vatem alat4

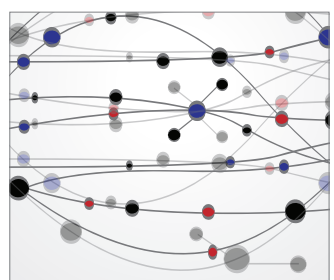

\section{The Scientific} World Journal
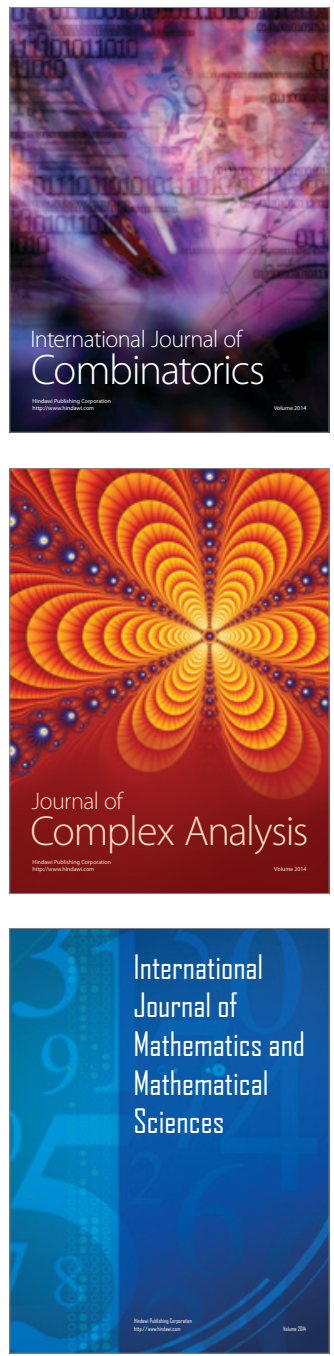
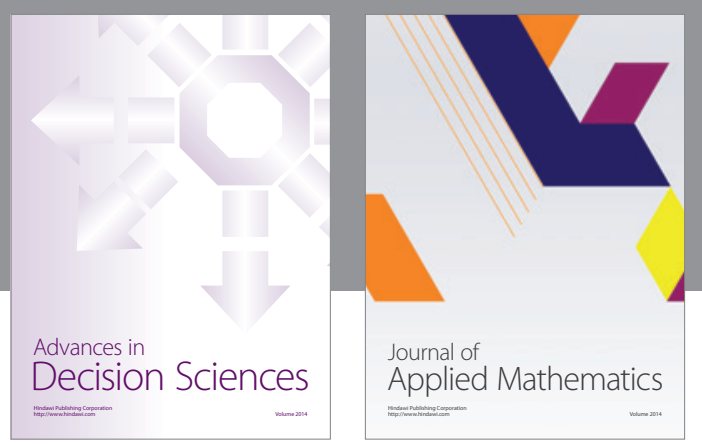

Algebra

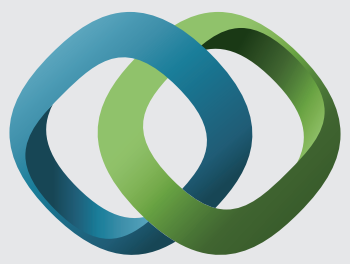

\section{Hindawi}

Submit your manuscripts at

http://www.hindawi.com
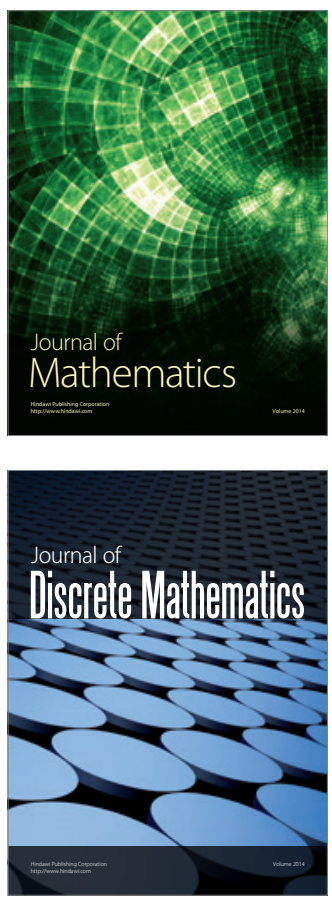

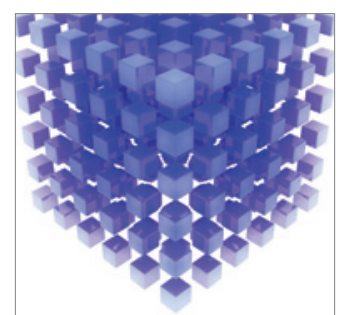

Mathematical Problems in Engineering
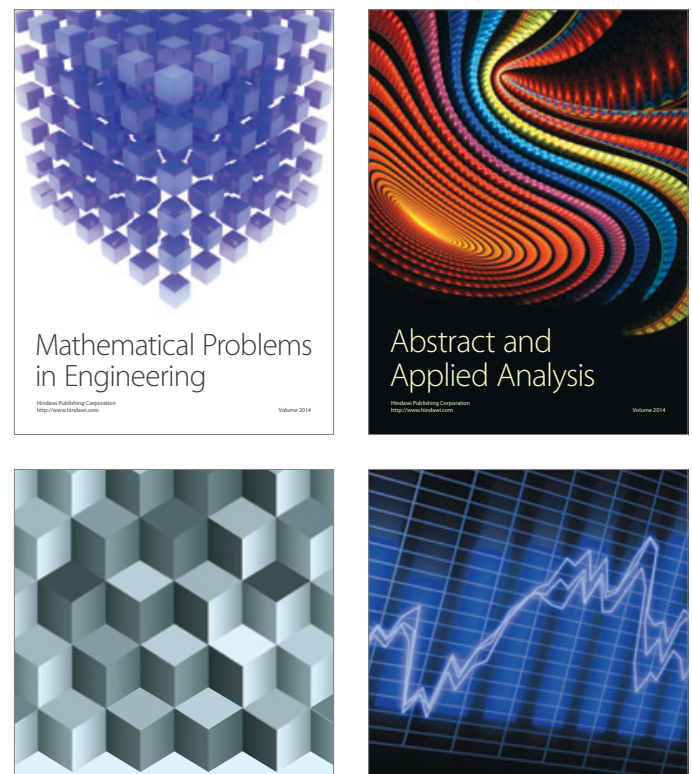

Journal of

Function Spaces

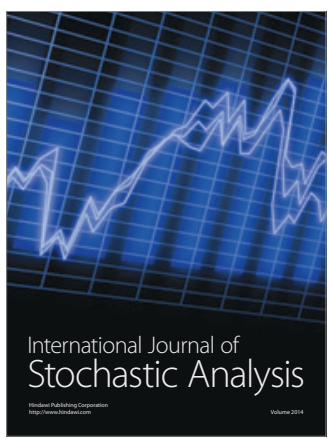

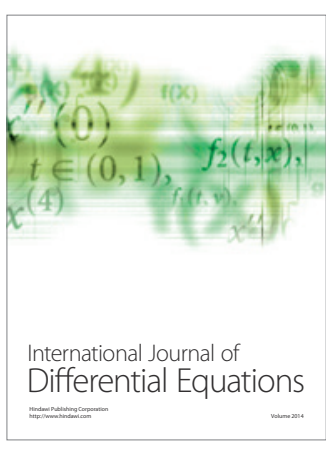
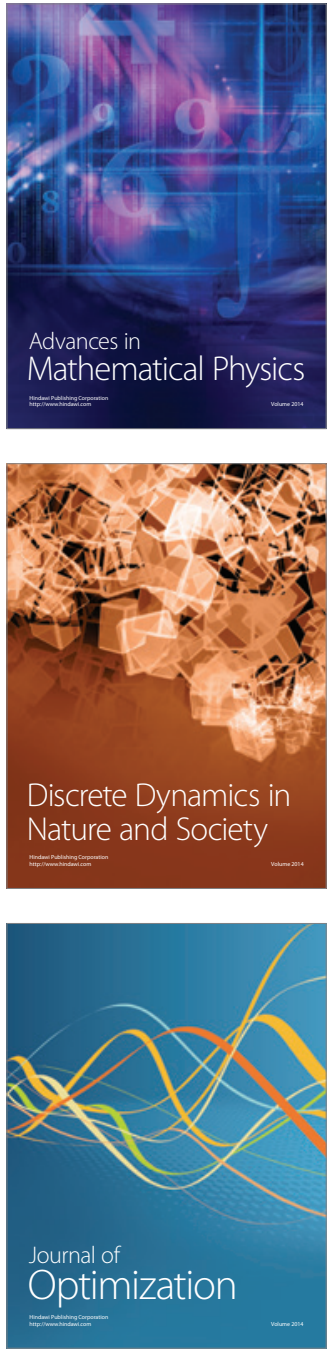